$$
\begin{aligned}
& \text { تأثير حجم وشكل وتوزيع العيوب السطحية على } \\
& \text { عملية التشكيل لصفائح الألمنيوم } \\
& \text { احمد نافع راشد }
\end{aligned}
$$

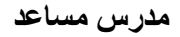

$$
\begin{aligned}
& \text { جامعة الموصل / قسم الهندسة الميكاتيكية } \\
& \text { الخلاصة }
\end{aligned}
$$

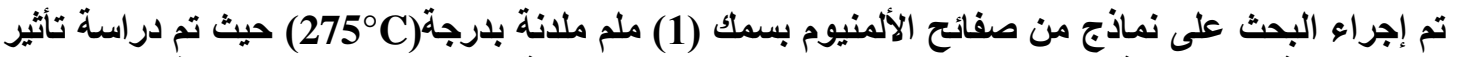

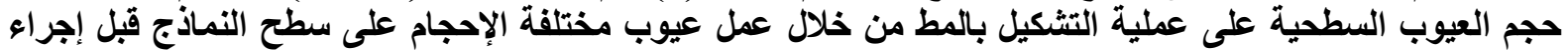

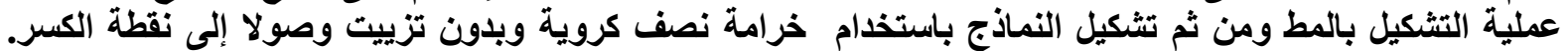

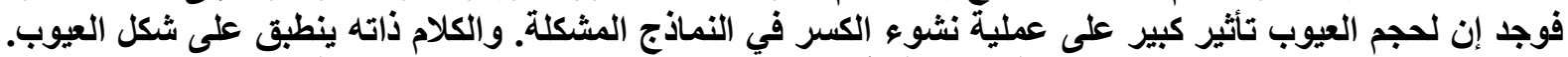

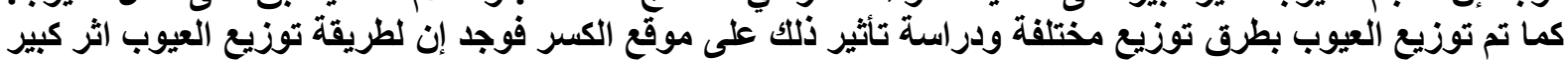

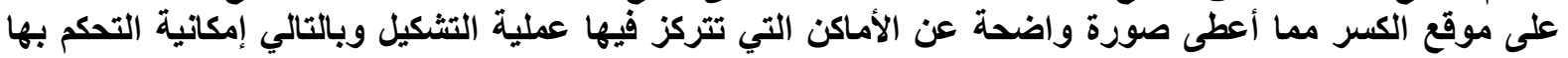

\title{
Effect of size, shape and distribution of surface defects on the forming of aluminum sheet
}

\author{
Ahmed Nafie Rashid \\ Assistant Lecturer \\ Mosul University / Mechanical Engineering Department
}

\begin{abstract}
The research was conducted on samples of aluminum sheet with $1 \mathrm{~mm}$ thickness, annealed at $\left(275 \mathrm{C}^{\circ}\right)$. To examine the effect of the size of surface defects on the stretch forming by introducing defects of different sizes on the surface of the sheet before forming process.Then forming the samples using a hemispherical punch without lubrication up to the fracture point. It was found that the defects size have a big effect on the fracture initiation and its propagation. The same result was found for the defect shape. Also the defect distribution was studied, where the defects distribution shows big effect on fracture position, which gave a clear picture of the forming is concentrated. Giving the opportunity to control forming and reduce the fracture.
\end{abstract}

Keywords: Aluminum, Stretch forming, Surface defects. 


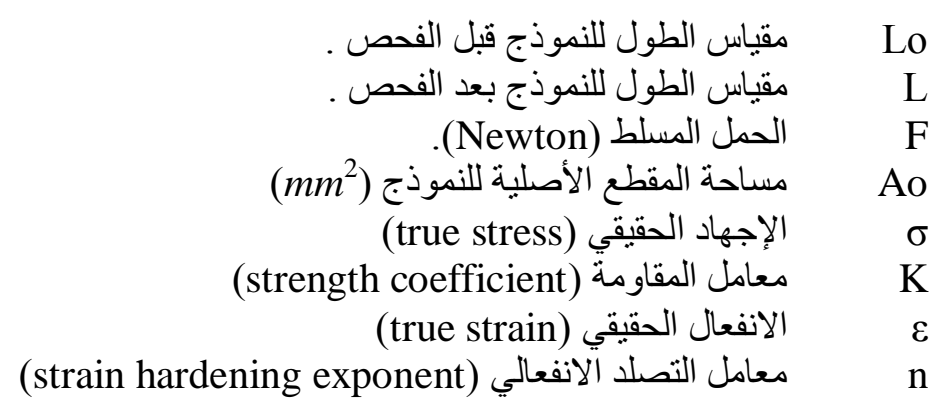

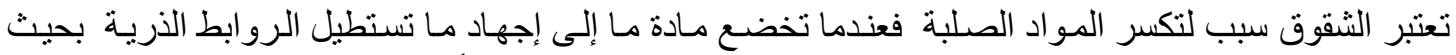

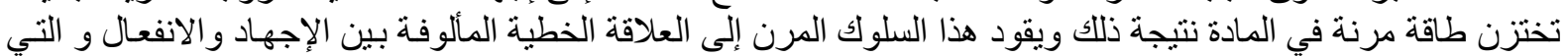

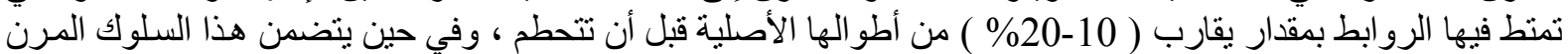

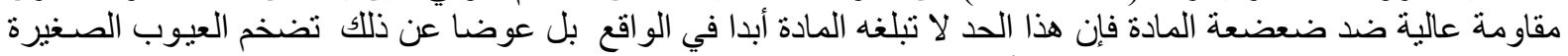

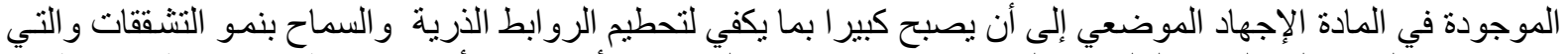

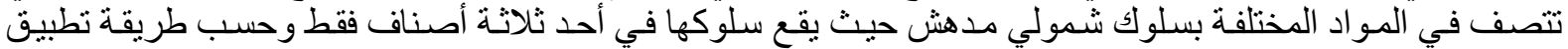

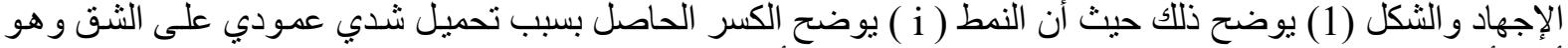

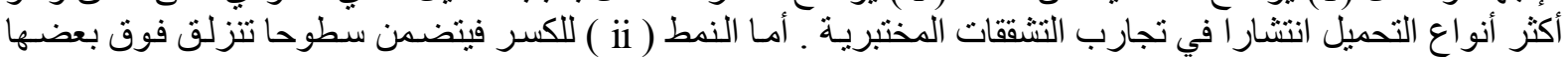

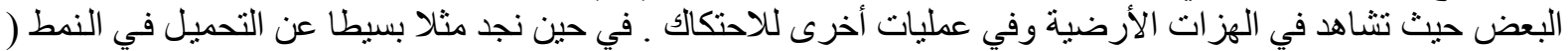

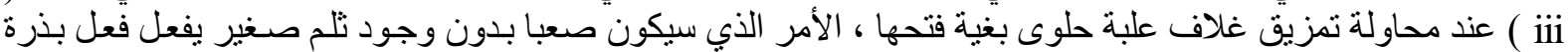

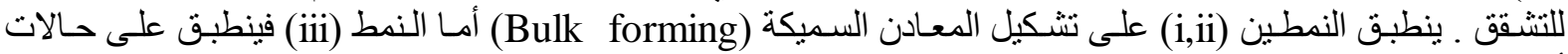

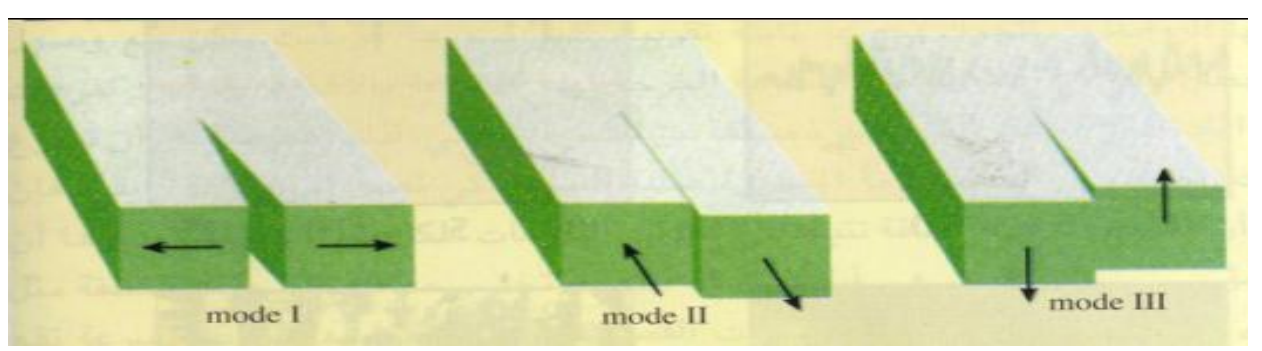
أخرى.

$$
\text { الثكل (1): يبين أنماط الكسور }
$$

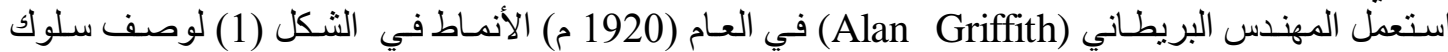

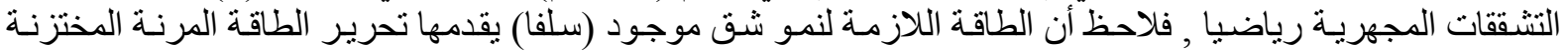

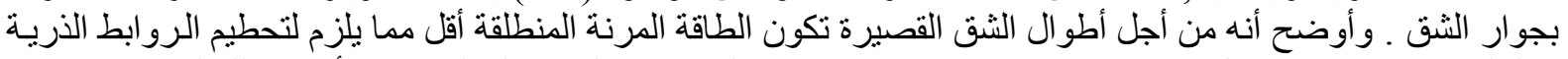

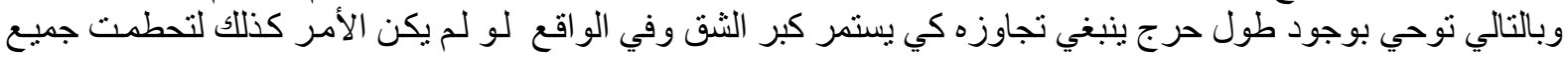

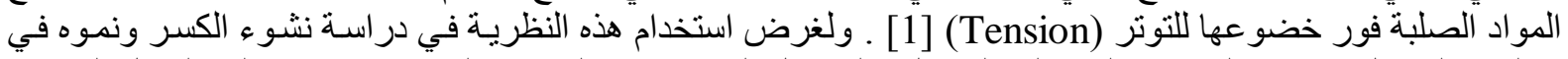

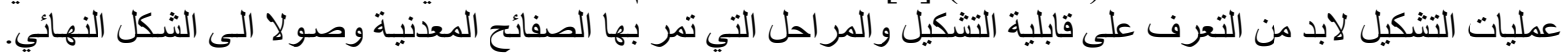

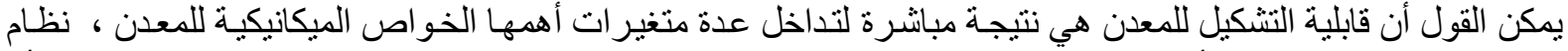

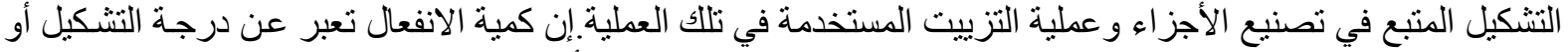

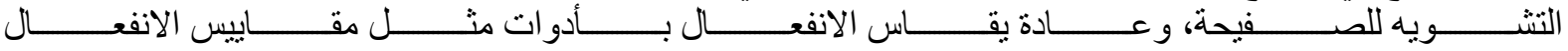
كما يمكن التعبير عن الانفعال الحاصل بفعل إجهاد الثد رياضيا بالمعادلة التالية[1,2]:

$\mathrm{e}=\mathrm{L}-\mathrm{Lo} / \mathrm{Lo}$

ويطلق على هذا الانفعال بالانفعال الهندسي (Engineering strain). أما الانفعال الذي يطلق عليه الانفعال الحقيقي فيحسب من المعادلة التالية : (true strain) 
$\varepsilon=\operatorname{Ln}(1+\mathrm{e})$

ويمكن التعبير عن الإجهاد الهندسي (لنموذج فحص مسلط علية حمل) رياضياً :-

ولمعامل التصلد الانفعالي (strain hardening exponent) أهمية كبيرة في تشكيل المعادن فهو يعطي تصور

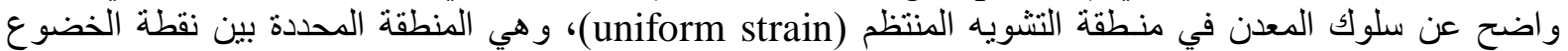

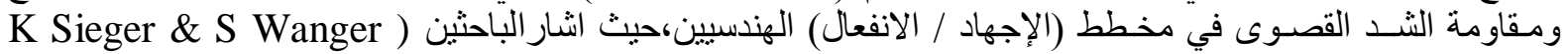

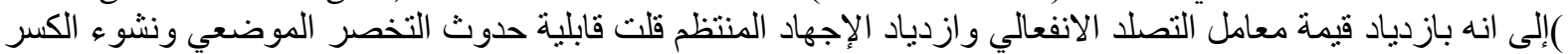
في عملية التشكيل بالمط وبهذا يمكن تسليط قوة اكبر على مركز القطعة المشكلة وبالتالي زيادة قابلية التشكيل. [3] و لإِيجاد الإدي

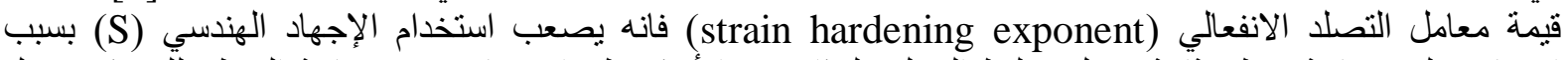

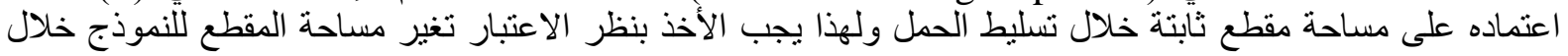
فحص الثد وبالتالي إيجاد الإجهاد الحقيقي (true stress) [4]من المبنة المعادلة التالية:

$\sigma=\mathrm{S}(1+\mathrm{e})$

ويحسب (n) من المعادلة التالية:

$\sigma=K \varepsilon^{\wedge} n$

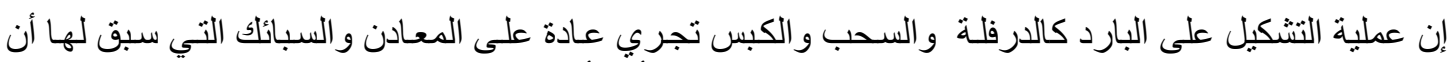

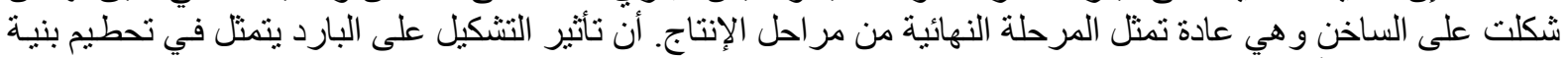

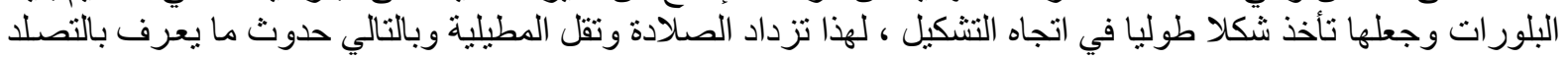

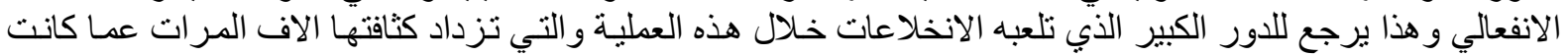

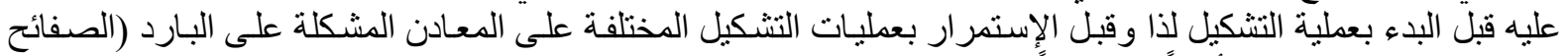

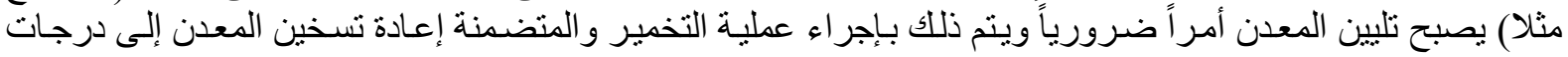
حرارة تكفي لحدوث تغييرات في البنية يعقبها التبريد البطئ في الفرن [2,5].

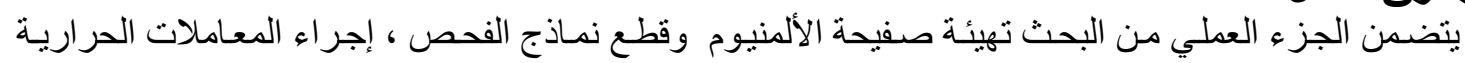

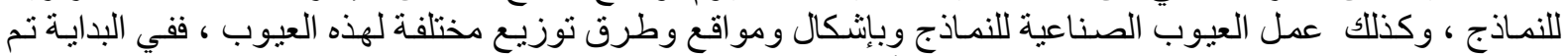

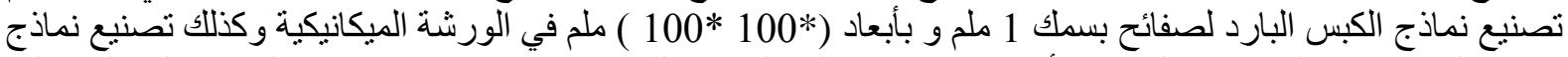

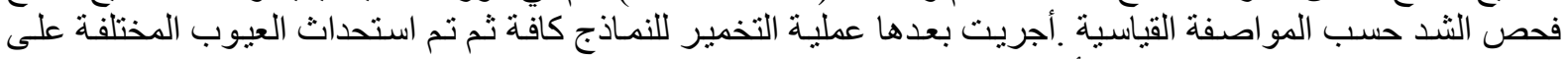

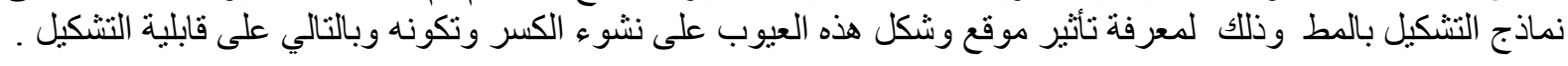

تهيئة المواد الأولية

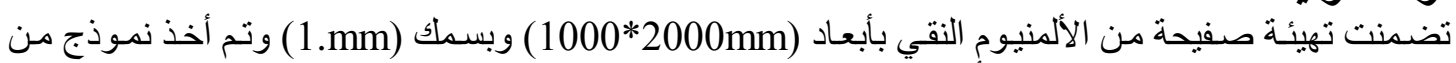

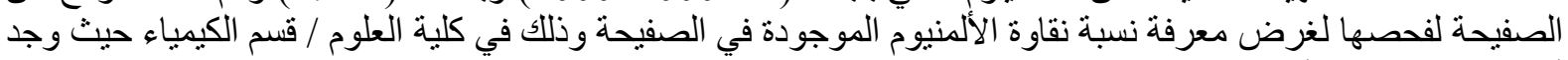

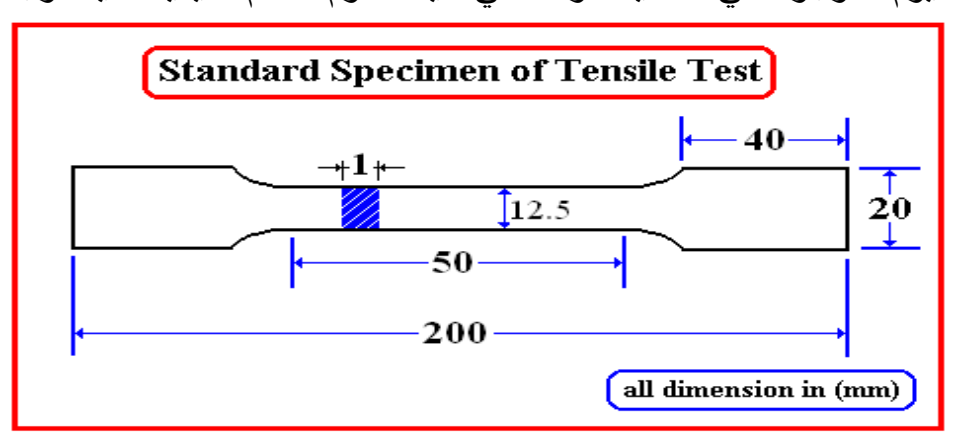

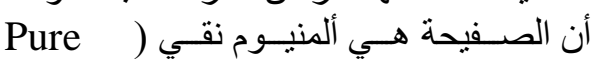
بانس (Aluminum

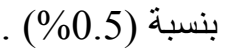

شكل (2) :نموذج فحص الثد حسب المواصفة القياسية

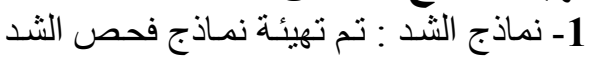
حسبب المو اصـفة القياسـية (ASTM370) و الثكل( 2) يبين ابعاد نموذج فحص الثند. 
2- نماذج اختبار التشكيل بالمط : تم تصنيع نماذج بأبعاد (100mm) وقد بلغ عدد النماذج المصنعة (80) قطعة .

المعاملات الحرارية (عملية التخمير)

أجريت عملية التخمير المزيل للإجهاد للنماذج باستخدام فرن كهربائي نوع (Electric Muffle Furnace )

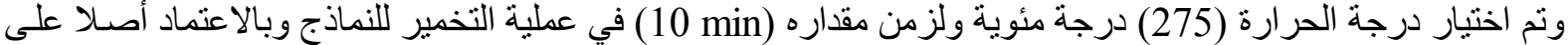
Temp. $\left({ }^{\circ} \mathrm{c}\right) \uparrow$

درجة حرارة إعادة التبلور للألمنيوم .و الثكل (3) يوضة ورتح مر احل عملية التخمير المستخدمة في هذه الدراسة .

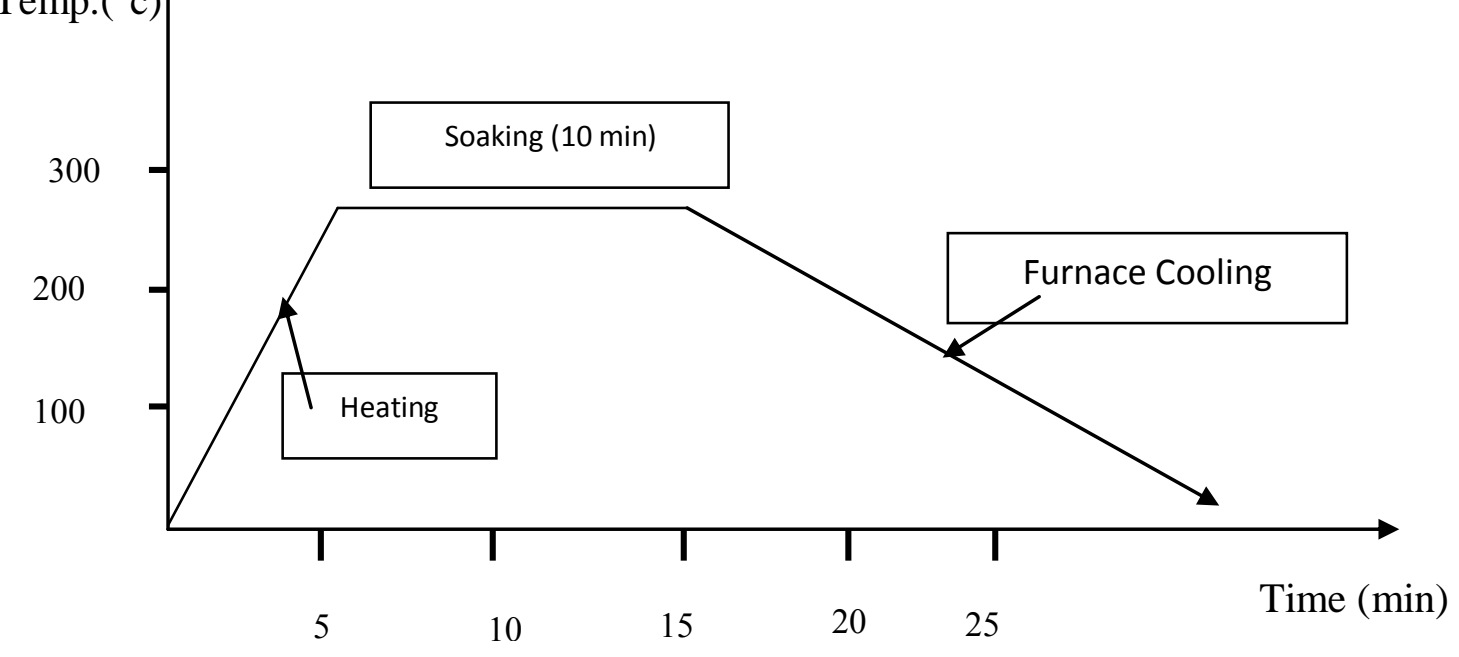

شكل (3) :مر احل عملية التخمير

اختيار موقع وشكل العيوب الخارجية

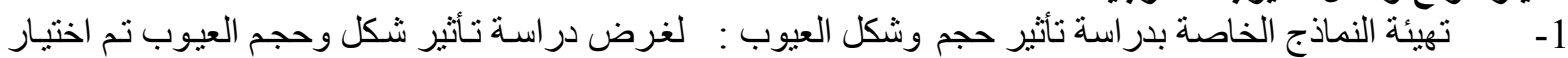
ثلاث حالات :- ت ت

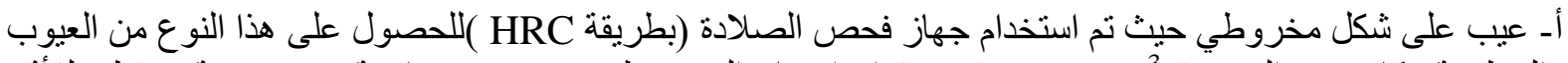

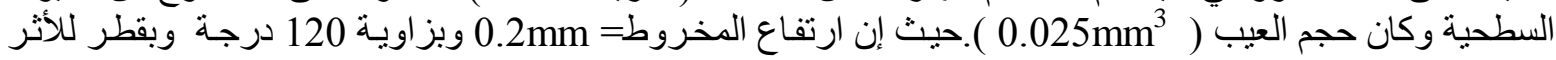

$0.692 \mathrm{~mm}$

$\mathrm{V}=1 / 3 \mathrm{HA}$

بـ عيب على شكل نصف كروي بقطر (1.26 mm) أي بحجم (1.047 mm³ حيث تم إستخدام جهاز فحص الصلادة $\mathrm{V}=4 / 3 \pi \mathrm{r}^{3}$ بطريقة HRB للحصول على هذا النوع ان العيوب السطحية.

ج- عيب على شكل نصف كروي بقطر (1.65mm) أي بحجم (2.35mm) حيث تم إستخدام أزميل حديدي وبطريقة يدوية للحصول على هذا النوع من العيوب السطحية.

$\mathrm{V}=4 / 3 \pi \mathrm{r}^{3}$

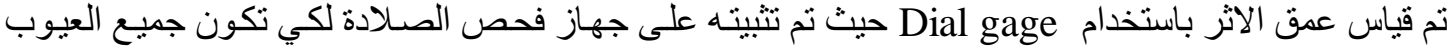

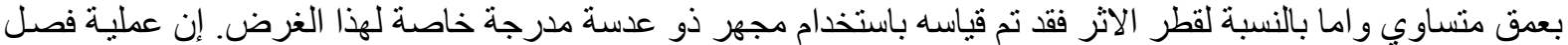

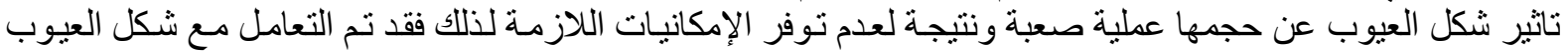

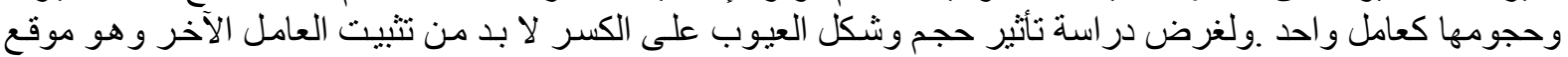

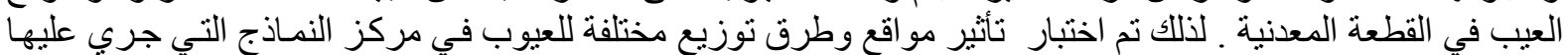

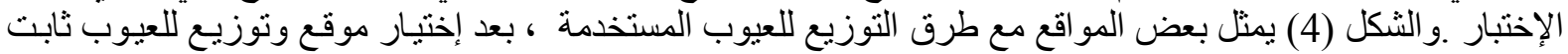

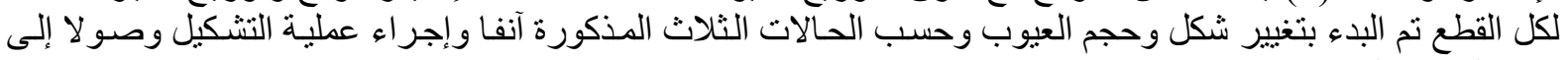

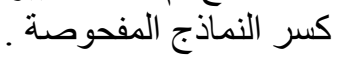




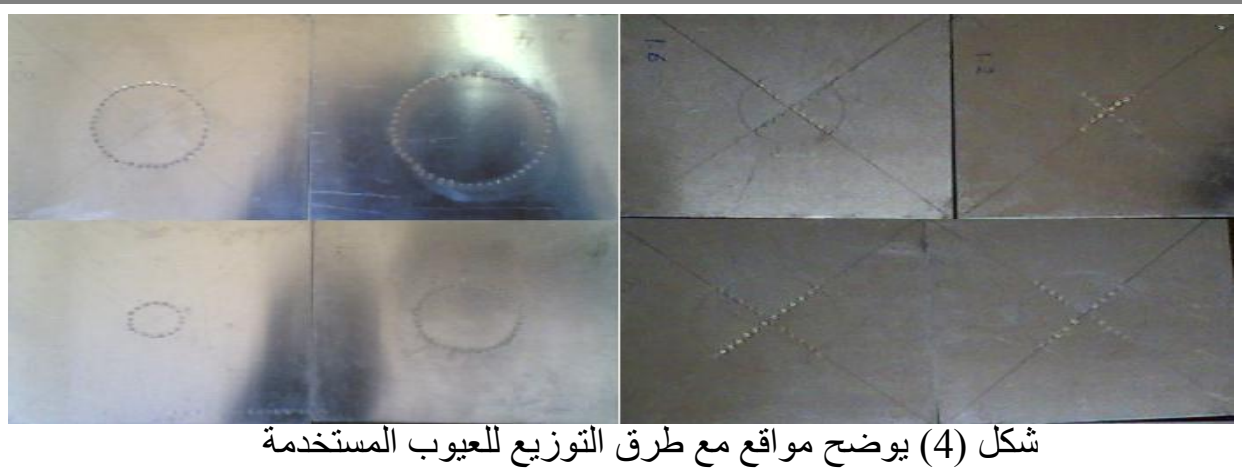

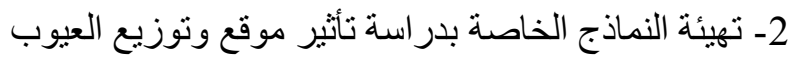

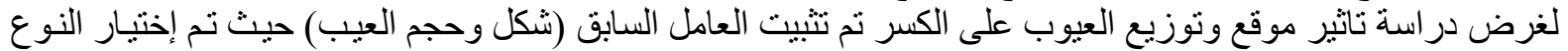

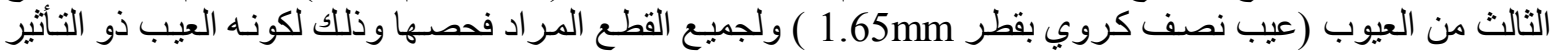
الأكبر وكما سنلاحظ من النتائج . وللتعرف على تأثير موقع وتوزيع العيوب على الكسر اختيرت مسافات مختلفة من مركز القطعة و على شكل دوائر متغيرة

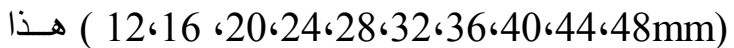

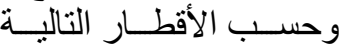
بالنسبة لتأثثر الموقع ـ أما بالنسبة لتأثير توزيع العيوب تم اختيار نوعين من التوزيع للعيوب :

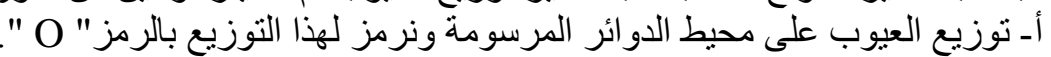

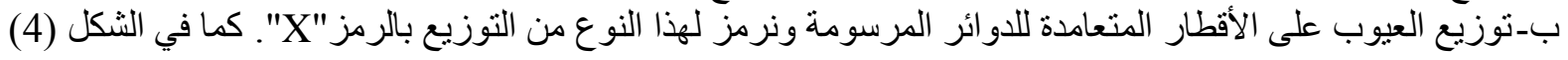

اختبار التشكيل بالمط يعتبر التشكيل بـالمط (Stretch Forming) من العمليـات المهمـة والأساسية و السـائدة في عمليـات التشكيل

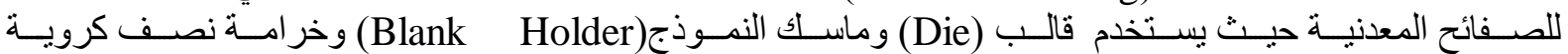
وتوضع الصفيحة المعدنية (النموذج) على القالب ثم تكبس بالخر امـة أب تمط المسادة فوق (Hemispherical Punch)

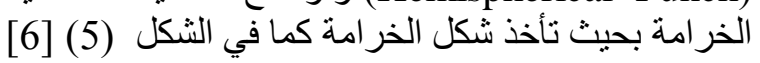

تم أجر اء عملية المط على النماذج بوساطة خر امة نصف كروية (Hemispherical Punch) باستخدام جهاز

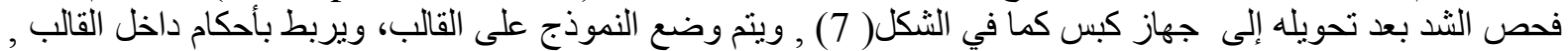

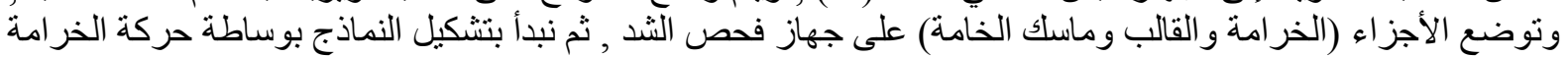

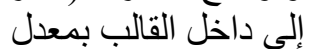

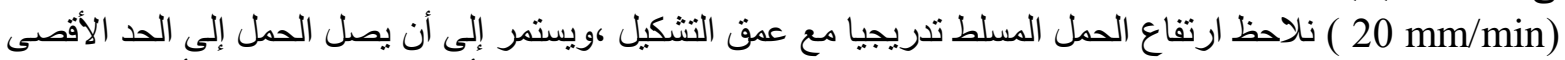

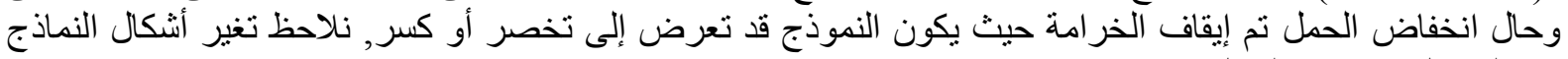

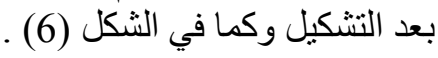
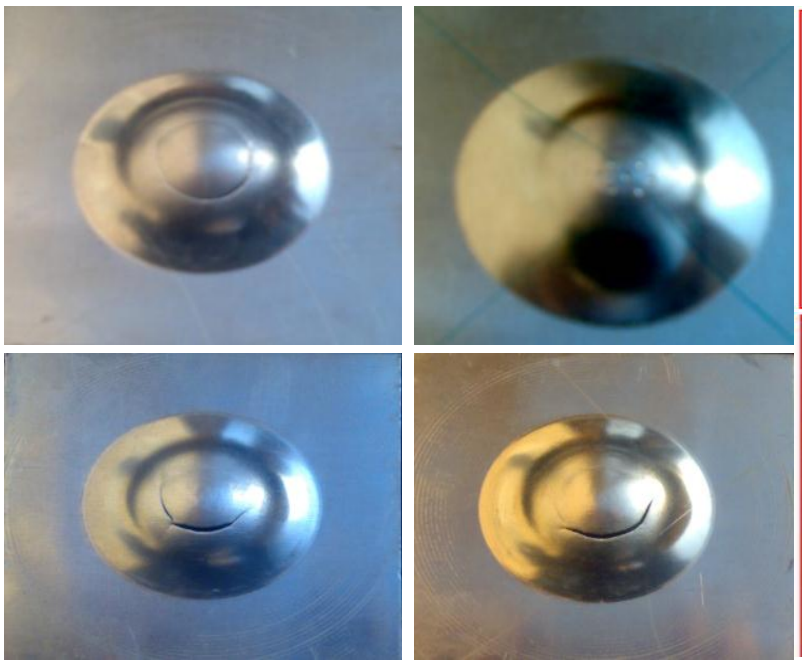

شكل (6) نماذج بعد الكبس

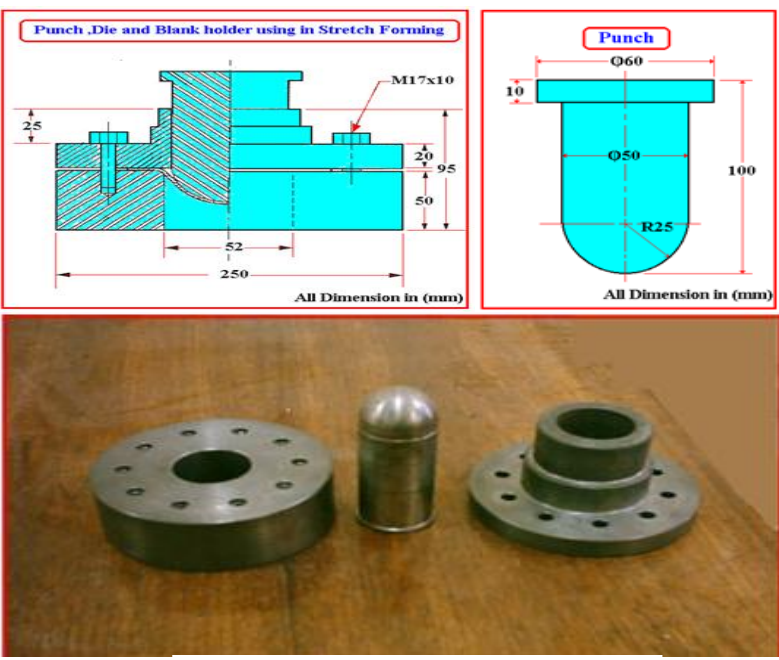

شكل (5) الخر امة و القالب ومثبت 


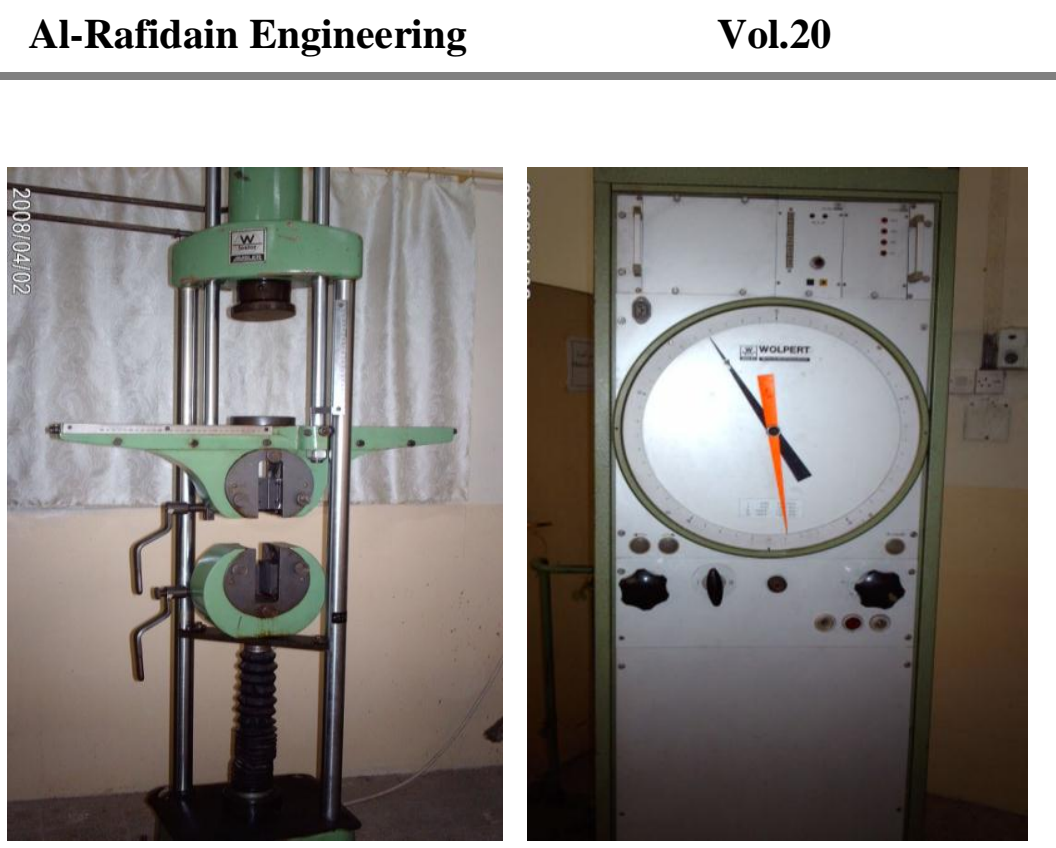

No.1

Feb. 2012

$$
\text { شكل (7) جهاز فحص الثند }
$$

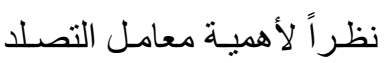

فحص الثد

اجـري فحص الثـــ باستخدام

جهاز فحص الشـد نـوع ( Wolpert )

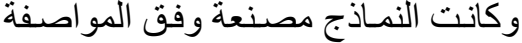
القياســية الأمريكيـــة (ASTM370) و النشكل (7) يوضـح الجهـاز المسـتخدم في الفحص. النتائج

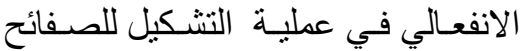

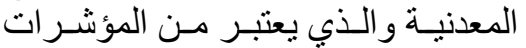
الهامة في معرفة قابلية التشكيل حيث تم تم n- حساب قيمة معامل التصلد الإنفعالي لئيل

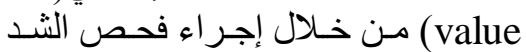

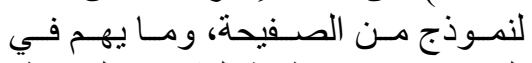

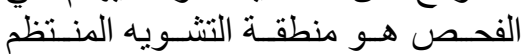

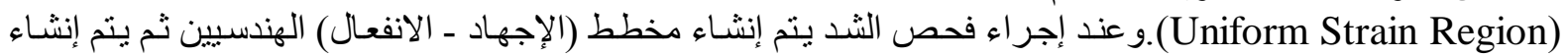

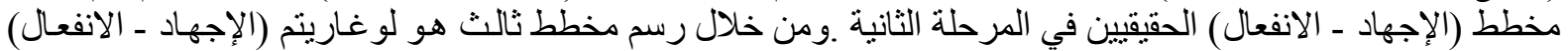

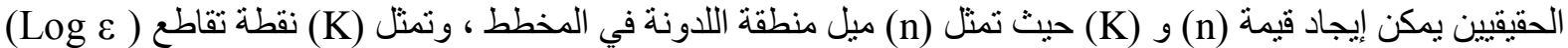

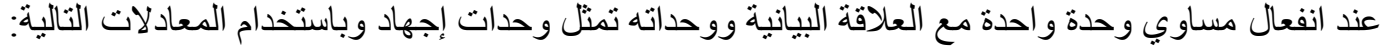

$\sigma=K \varepsilon^{n}$

$\log \sigma=\log k+\log \varepsilon$

If $\log \mathrm{K}=0$

$\mathrm{n}=\log \sigma / \log \varepsilon$

at $\varepsilon=1$

$\log \varepsilon=0$

$\log \sigma=\log k$

$\mathrm{Ao}=12.5 \mathrm{~mm}^{2} \quad / \quad \mathrm{Lo}=50 \mathrm{~mm} \quad / \mathrm{n}=0.25 / \mathrm{K}=302.4 \mathrm{MPa}$

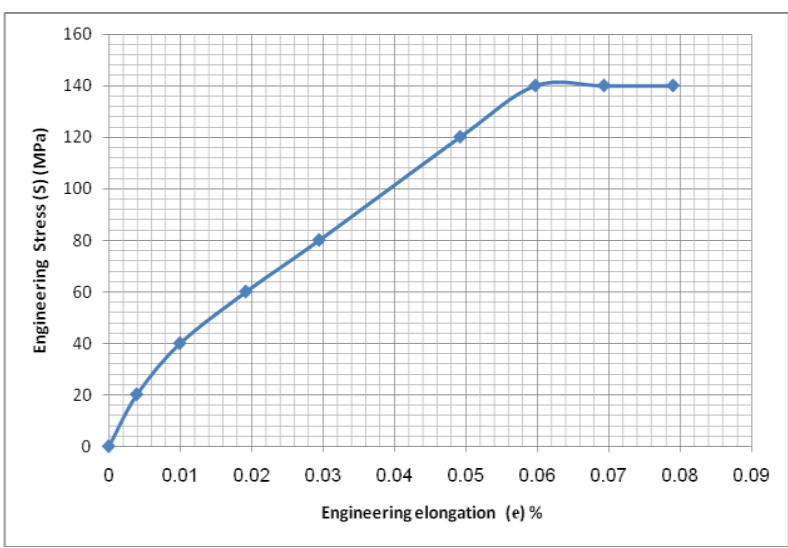

شكل (8) يبين العلاقة بين (الإجهاد - الإنفعال) الهندسي

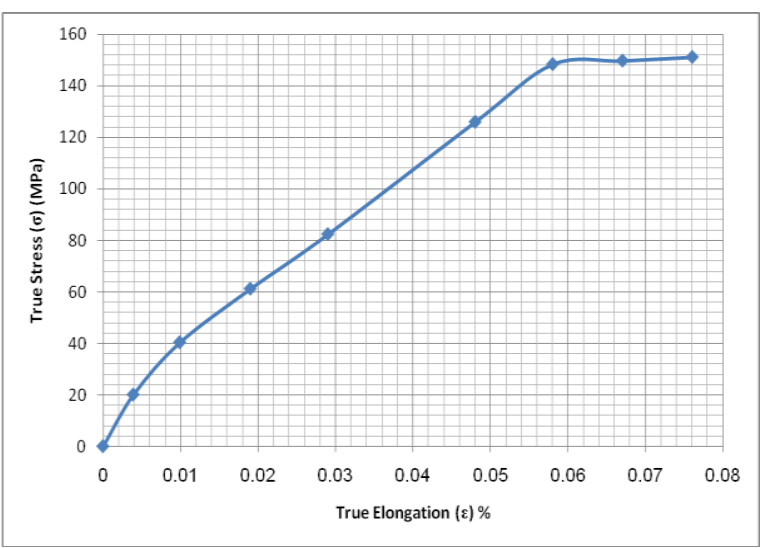

شكل (9) مخطط يبين العلاقة بين (الإجهاد ـ الإنفعال) الحقيقي 


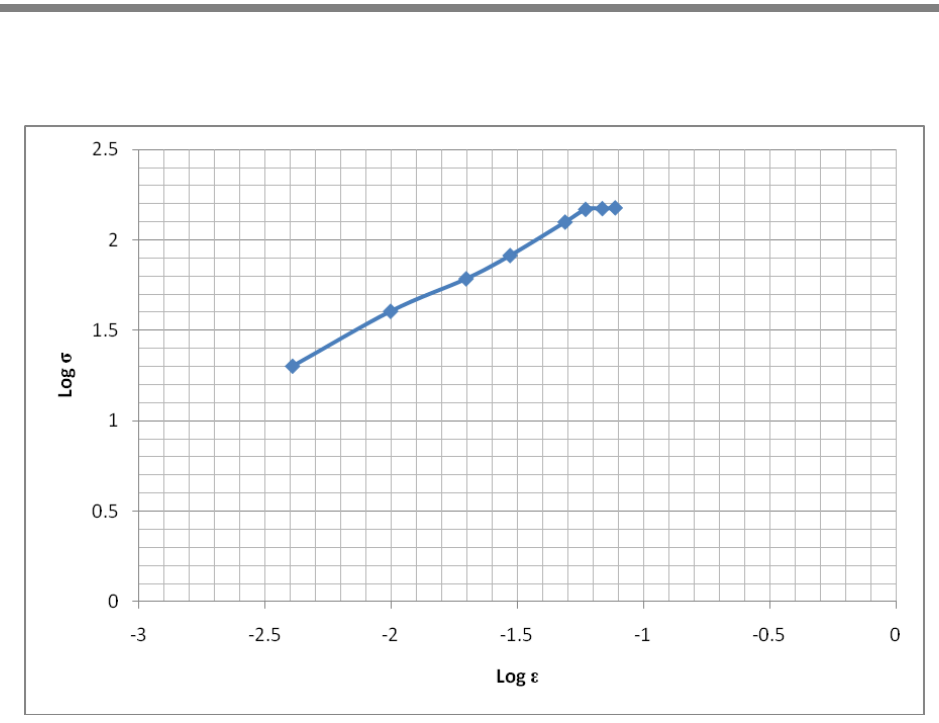

التحليل و المناقشة

تـم مناقثـة النتائج على عـدة محساور وكالاتي:

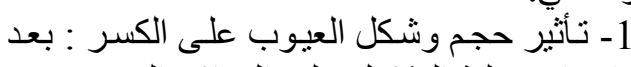

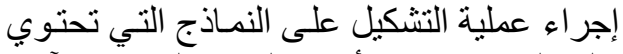

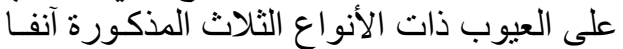

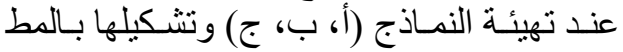

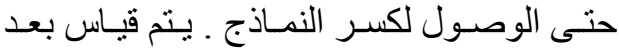

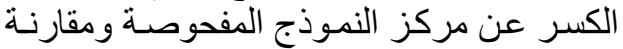

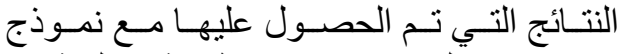

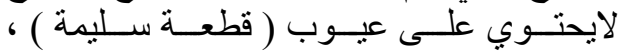
والجدول (1) يبين بعد الكسر عن مركز ثناث

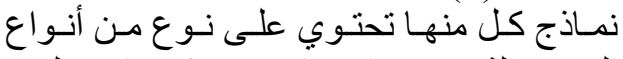
العيوب الثناث ومقارنتها مع نموذج رئر ابع سليم .

شكل (10) مخطط يبين العلاقة بين (لو غاريتم الإجهاد - لوغارينت الإنفعال) الحقيقي

الجدول (1) يبين بعد الكسر عن مركز ثناث نماذج كل منها تحتوي على نوع من أنواع العيوب الثلاث ومقارنتها مع

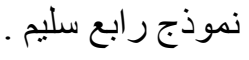

\begin{tabular}{|c|c|c|c|}
\hline 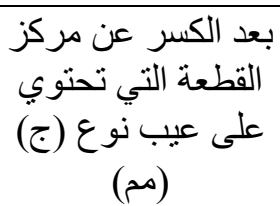 & بعد الكسر التي تحنت مركزي & بعد الكسر عن مركز التي تحتوي & بعد الكسرة عن مركز السليمة \\
\hline $8 \mathrm{~mm}$ & $8.5 \mathrm{~mm}$ & $9 \mathrm{~mm}$ & $9 \mathrm{~mm}$ \\
\hline
\end{tabular}

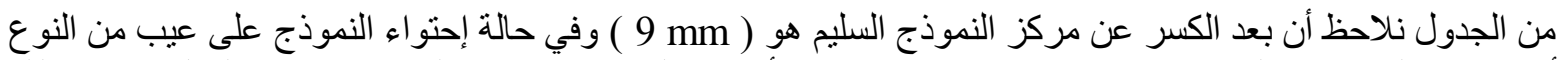

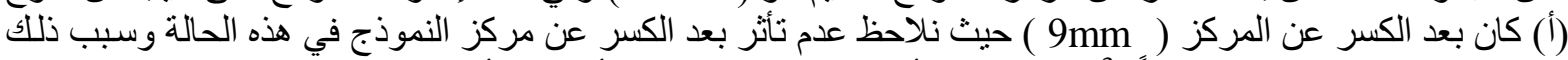

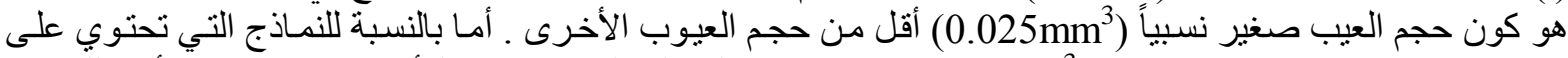

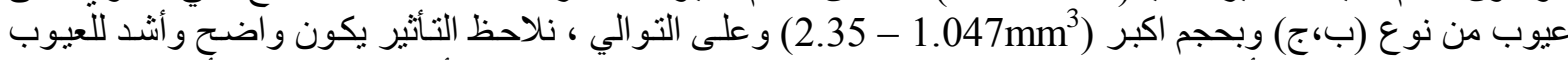

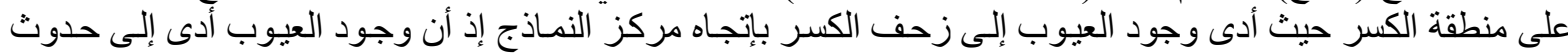

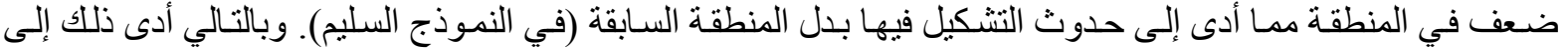

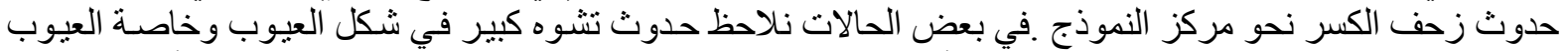

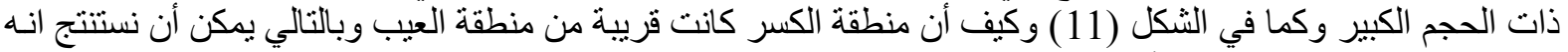

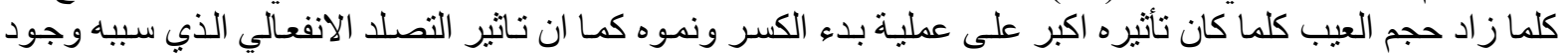

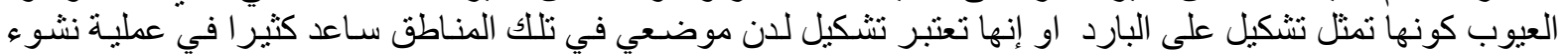

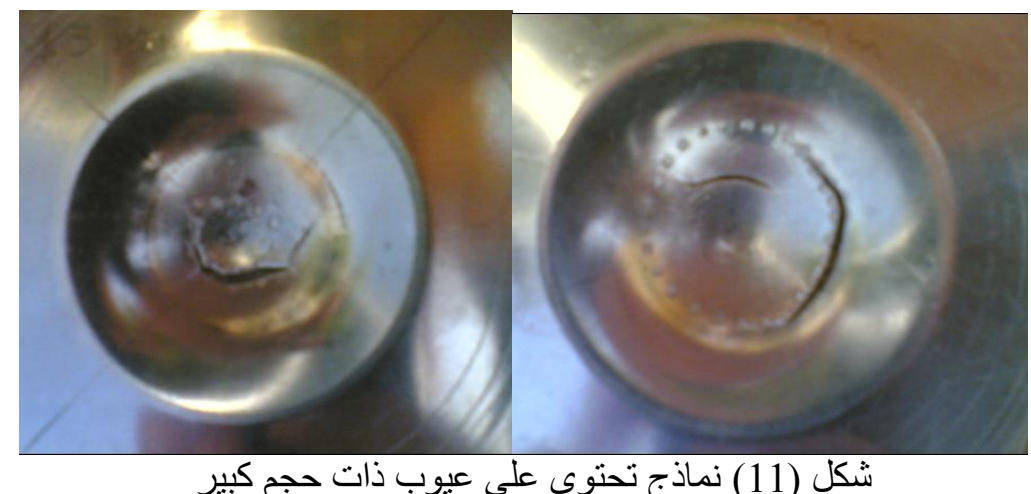


أما بالنسبة لنكل العيب فقد اشار الباحث Henry حول شكل العيب وتأثثيره على الكسر إن العيوب كلما كانت تحتوي على

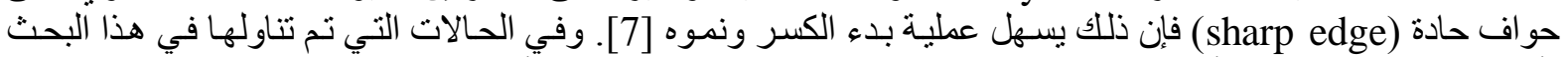

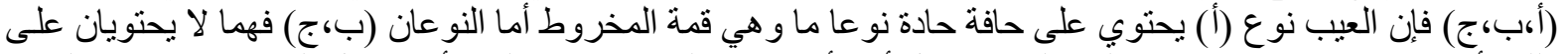

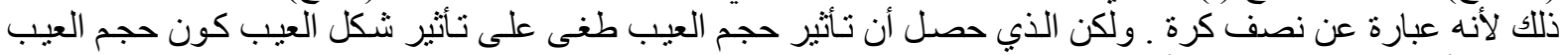

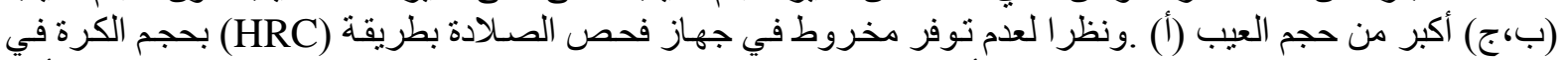

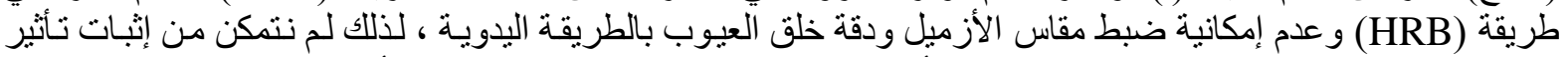

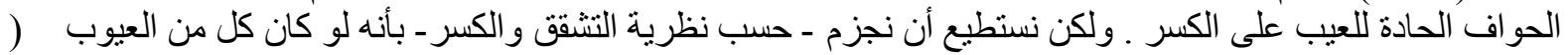
أ ، ب ، ج ) لهم نفس الحجم لكان تأثير العيب نوع ( أ ) على الكسر أكبر من الأنواع الأخرى .

2- تأثير موفع العيوب على الكسر : لغرض التعرف على تأثثير موقع العيوب على الكسر ومن نتائج الفحوصـات تم رسم

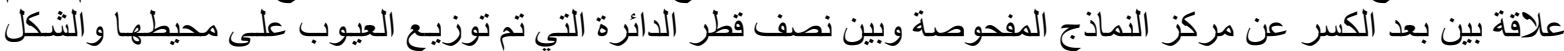

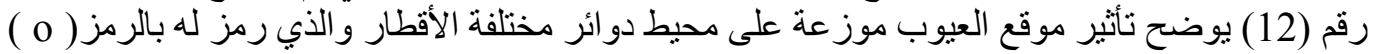

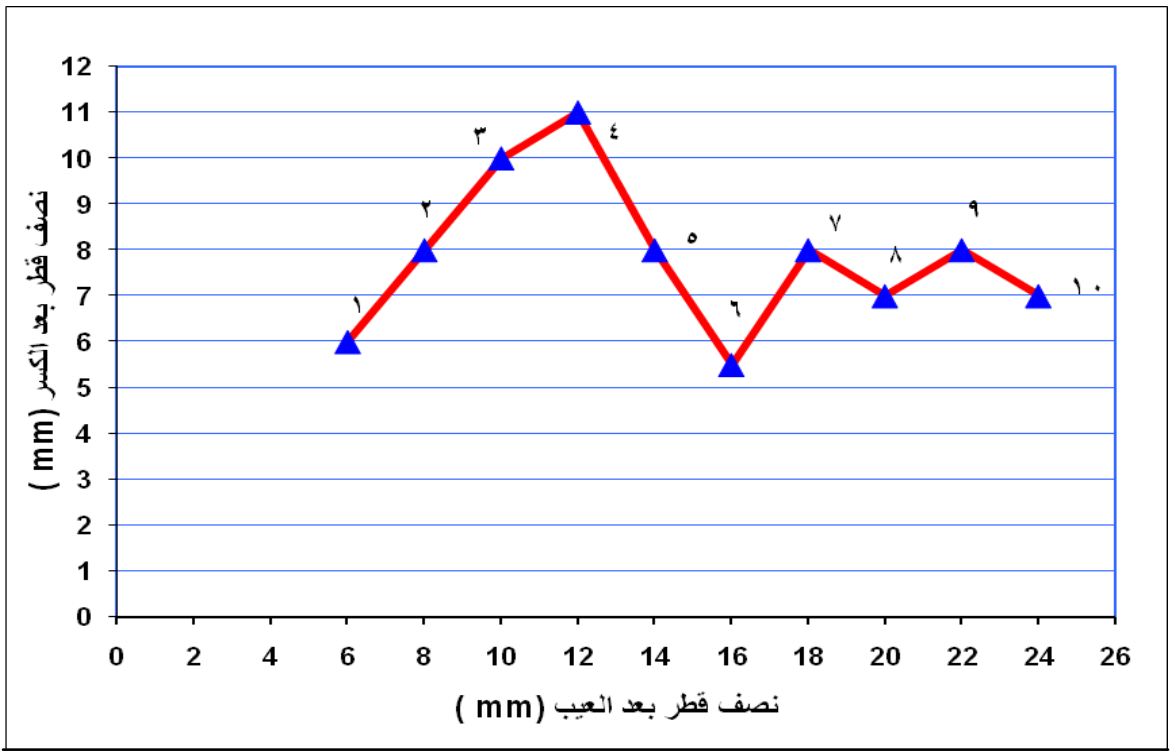

شكل (12) مخطط يبين العلاقة بين نصف قطر بعد الكسر مع نصف قطر بعد العيب

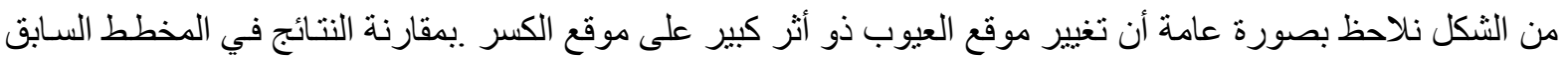

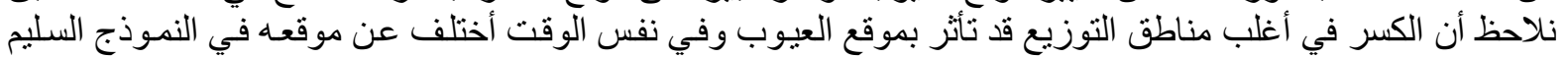

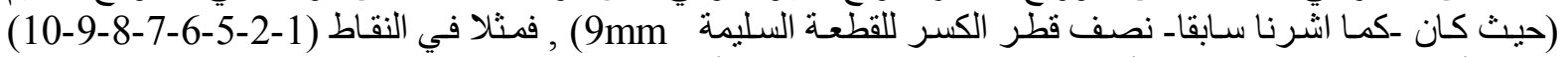

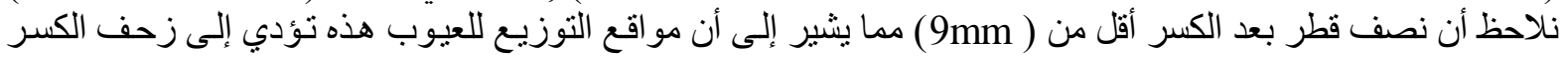

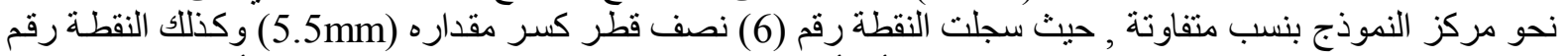
(1) حيث سجلت نصف قطر كسر مقداره (6mm) أب أن وجود العيوب في هذين الموقعين يعطيان أكبر زحف للكسر

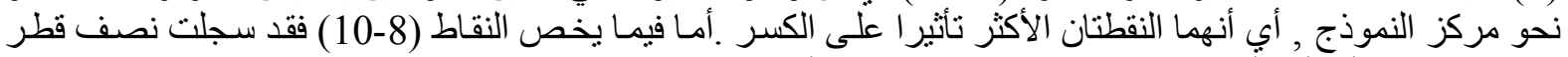

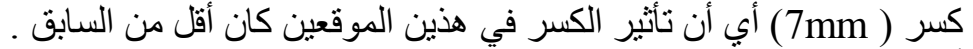

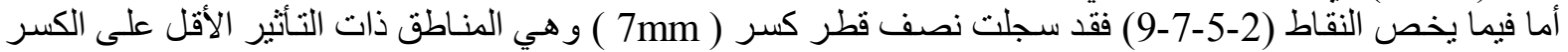

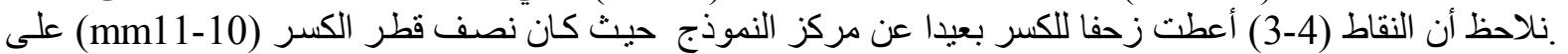

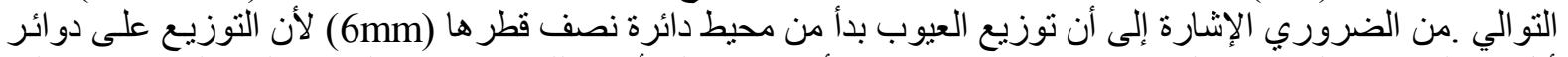

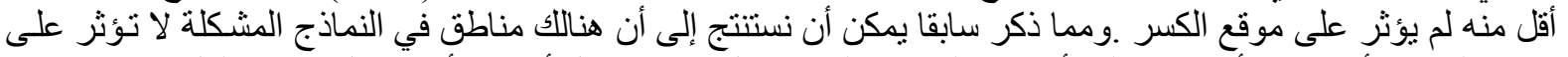

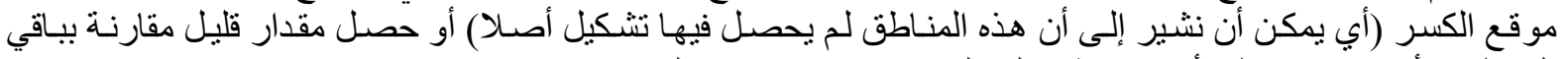

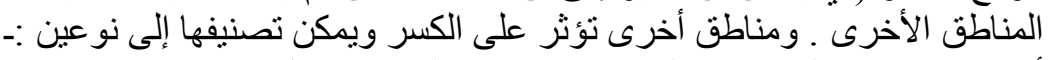

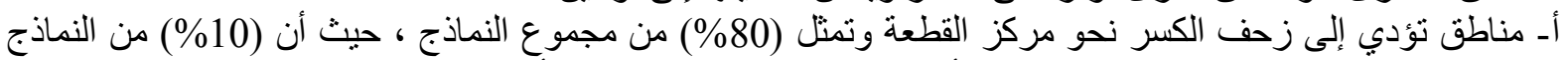

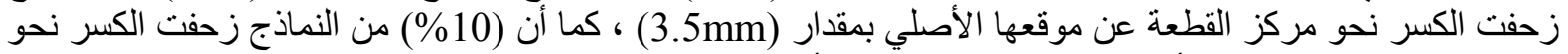
مركز القطعة عن موقعها الأصلي بمقدار (3mm) ، وأن (20\%) من النماذج زحفت الكسر نحو مركز القطعة عن 
موقعها الأصلي بمقدار (2mm) ، وأن (40\%) من النماذج زحفت الكسر نحو المركز عن موقعها الأصلي بمقدار . (1 mm)

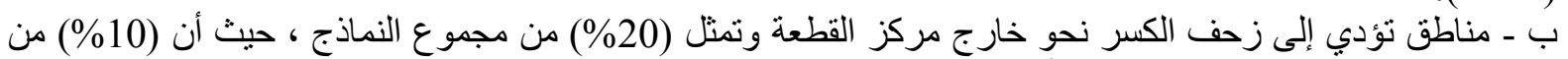

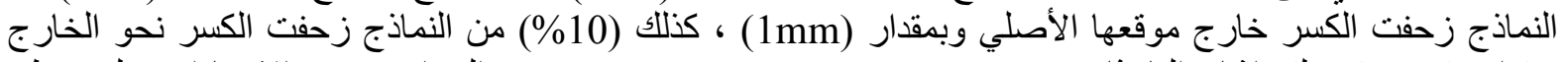

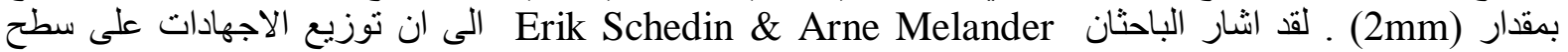

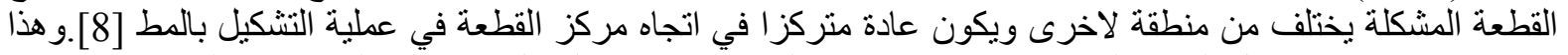

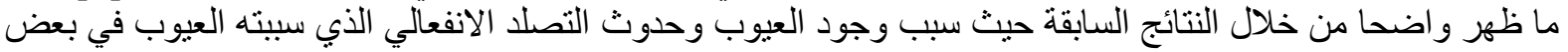
المناطق زحفا للكسر نحو مركز القطعة المشكلة وبنسبة 80\% من مجموع النتائج و هذا يفسر سبب زلفي زحف الكسر.

\section{تأثير طرق التوزيع للعيوب على الكسر}

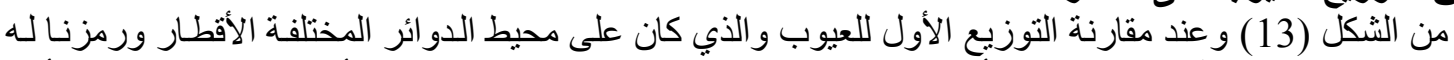

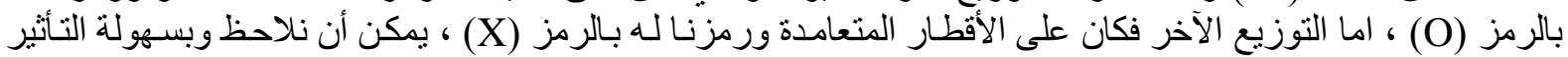

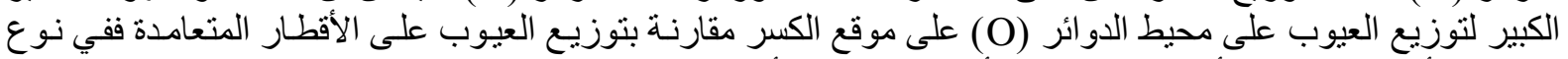

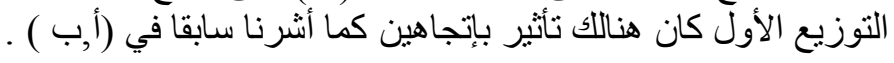

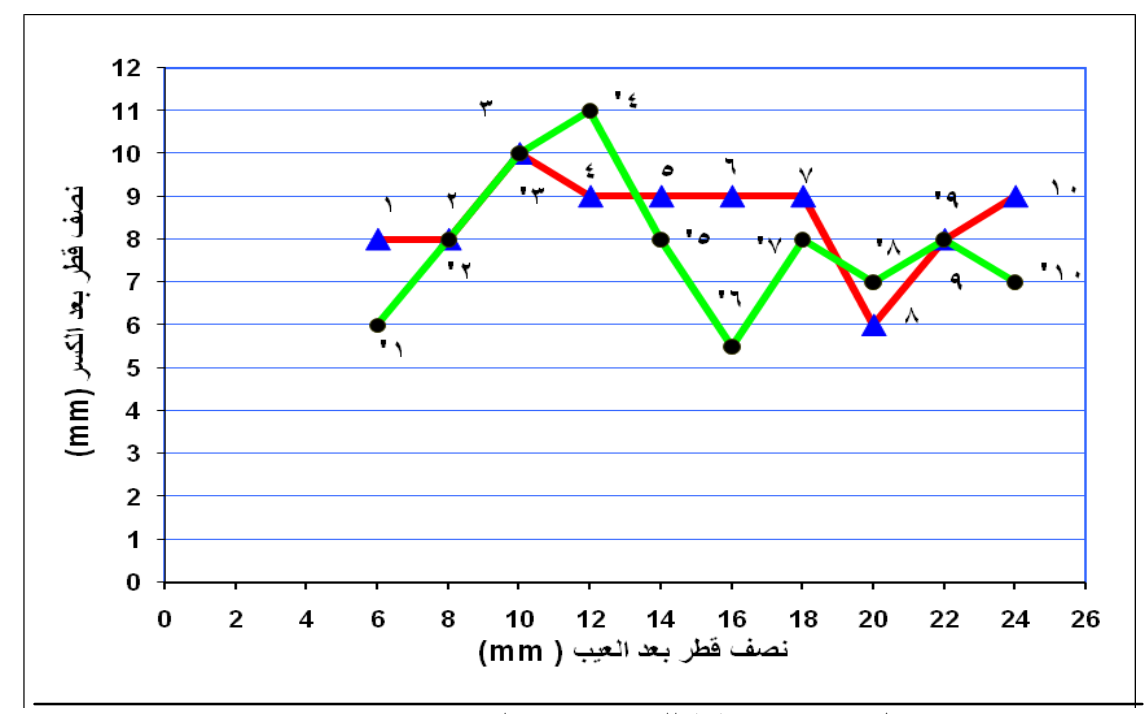

شكل(13): مخطط للمقارنة بين التوزيعين (O) و (X)

أما في التوزيع الثاني فمن الملاحظ أن التأثثير إنقسم إلى :-

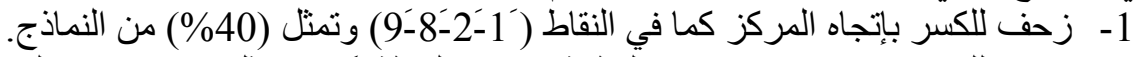

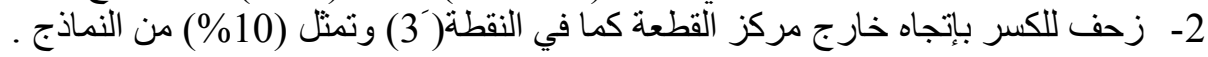

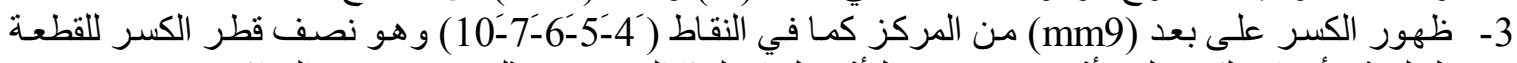

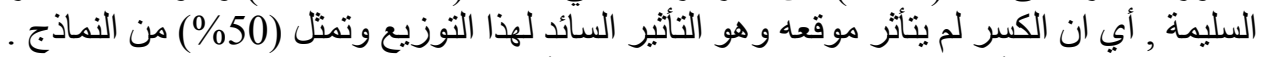

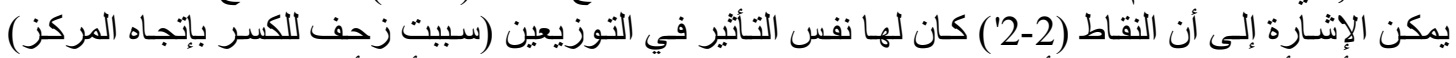

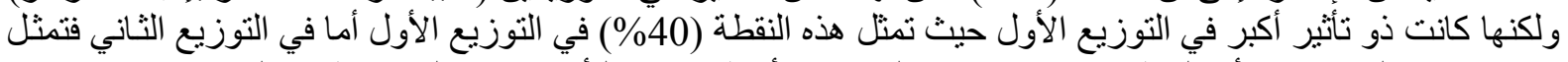

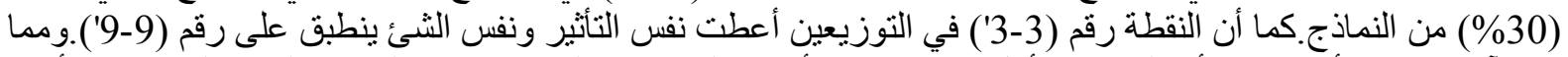

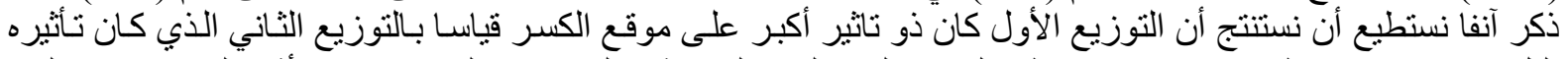

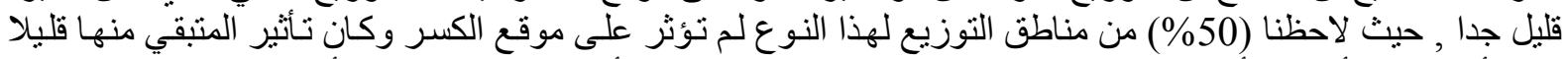

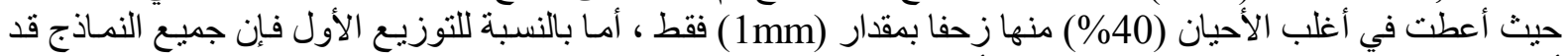

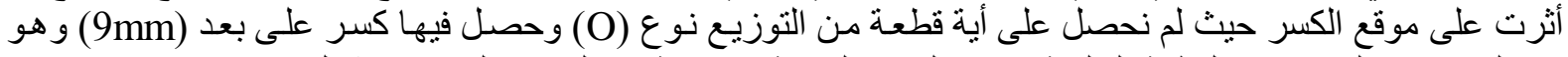

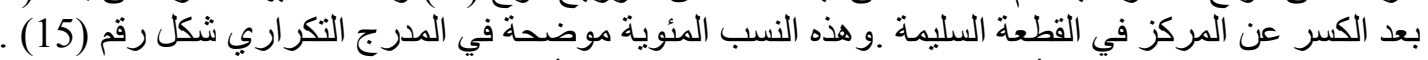

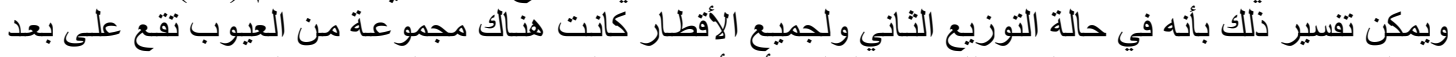
(9mm)

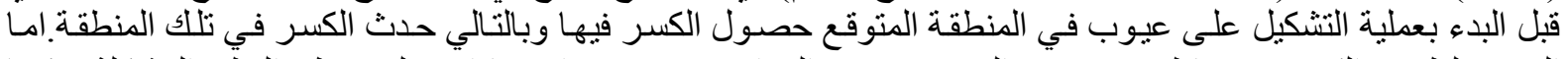

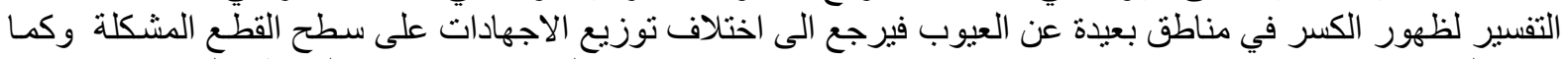

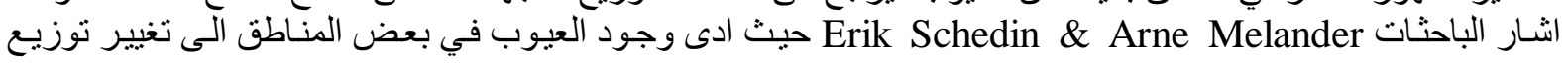


الاجهادات وتركيز ها في تلك المنطقة بدلا عن المنطقة المتوقع حصول الكسر [8] في كما يمكن تفسيره من ناحية أخرى وهي وكي

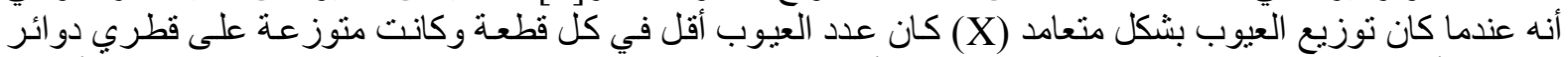

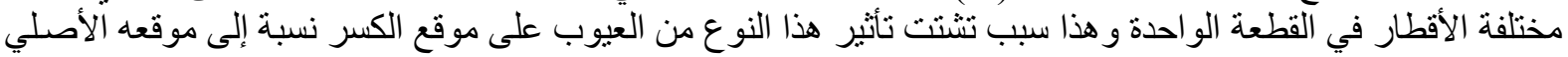

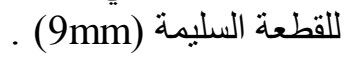

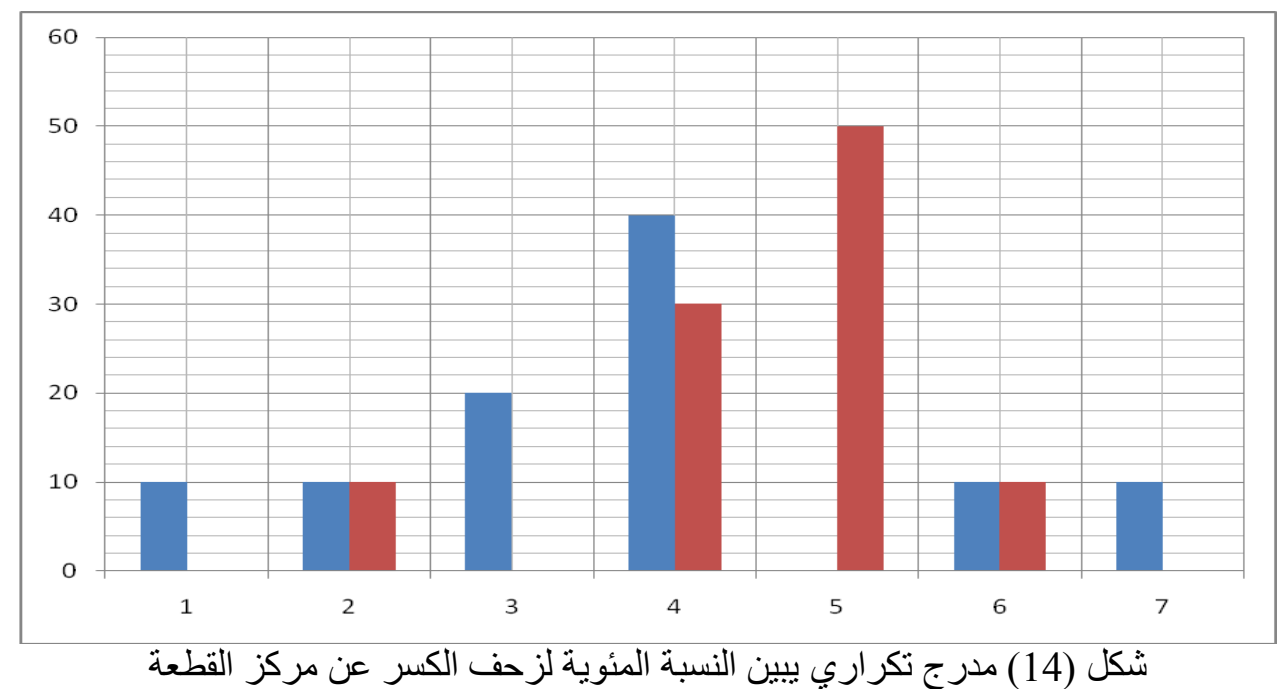

الاستنتاجات

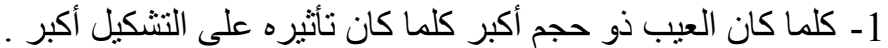
2- تكون عملية الكسر في حالة توزيع العيوب من نوع (O) غير ملئ منتظمة أبي إما تكون بعيدة أو قريبة من منطقة مركز

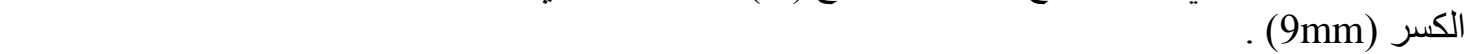
3- لوحظ من خلال الفحوصات عندما يكون نوزيع العيوب من نوع (X) أن أغلب مناطق الكسر تساوي (9mm) وهو كما موجود في القطعة السليمة .

1- مجلة عالم الذرة (مجلة هيئة الطاقة الذرية السورية) العدد 112 (تشرين الثاني/كانون الأول) لسنة 2007 الدئة

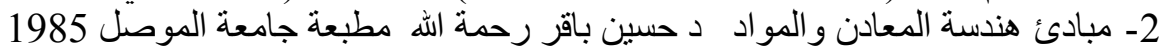

3- Formability Characteristics of Aluminum Sheet . K. Sieger and S. Wanger Stuttgart University.1994

4- Amp Journal Technology Vol.5 \june 1996

5- The Science and Engineering of Materials .Donald R Askeland 2004

6- Metal forming, fundamental and applications American society for metals 1985 Forming and Forging Vol. 141993

7- Deformable Bodies and their Material Behavior . Henry W. Has Lach, JR.2004

8- On the Strain Distribution During the Stretch Forming of Low and Hidh Strength Sheet Steel. Erik Schedin and Arne Melander ,Journal of Mechanical working Technology vol.15 1087

تم اجراء البحث في كلية ألهندسة = جامعة ألموصل 